\title{
Employee Tracking System
}

\author{
Prof. Punam Toke ${ }^{1}$, Abhishek Gole ${ }^{2}$, Aakash Khair ${ }^{3}$, Akshay Kshirsagar ${ }^{4}$, Shruti Khunte ${ }^{5}$ \\ Professor, Computer Dept, PVPIT, Pune, India ${ }^{1}$ \\ Student, Computer Dept, PVPIT, Pune, India ${ }^{2,3,4,5}$
}

\begin{abstract}
Every organization, whether big or small,has human resource challenges to overcome. Every organization has differentemployee management needs, therefore we design exclusive employee management systems that are adapted to your managerial requirements. This is designedto assist in strategic planning, and will help you ensure that your organization isequipped with the right level of human resources for your future goals.Also, for those busy executive who are always on the go, our systems come withremote access features, which will allow you to manage your workforce anytime, at all times. These systems will ultimately allow you to better manage resources. One of the main features in employee management system is time tracking foremployees. Effective time tracking mechanism saves both time and money for theorganization.
\end{abstract}

Keywords: Information system, Database system, DBMS, employee table, table fields, primary key, foreign key, relationship, sql queries, controls.

\section{INTRODUCTION}

Managing human resources in today's dynamic environment is becoming more and more complex as well as important. In any organization, employee management is very important. It is an aspect widely practiced in all workplaces. Employee Identification and personal verification technologies are becoming a great concern to organizations because of increase in security breaches and transaction fraud. Here the paper has looked into an efficient employee management system using fingerprint. For this purpose the employees necessary information such as name, sex, ID number and fingerprints are compiled and stored in the Database. When attendance is calculated, the daily fingerprints are matched with the stored fingerprint by using the scanner. If fingerprint is matched, then attendance is accepted otherwise it is rejected.

Fingerprints, are impression of the ridges on the end of our fingers and thumbs. Human beings have used fingerprints for personal identification for centuries, and they have used them for criminal investigations for more than 400 years. The validity of fingerprints as a basis for personal identification is thus well established. Therefore, no two persons have exactly the same arrangement of pattern, and the patterns of any one individual remain unchanged throughout life. Using fingerprint for identification and authentication is very important because of it's unique nature. No two person's fingerprint are the same and this will overcome the limitations of the existing system where one person can sign for another. Using this system, No one can thump print for another.

In the paper, Section II is on some related concepts on fingerprint, section III is on proposed work using fingerprint. Section IV is on experimental results and section $\mathrm{V}$ is the conclusion.

\section{EXISTING SYSTEM}

People have different personalities and work ethics .So in order to manage their work efficiently and fairly, there has to be a system in place to allocate tasks to different workers. Currently a manual system will provide most of the requirements for this project. Although noble the manager has little it control over his business. In a manual system data is stored in a cabinet. Files are thus often misplaced or lost. And at times is difficult to find relevant files. Records for stocks are also not always filed correctly and thus information is not centralised and not easily accessible.

\section{PROPOSED SYSTEM}

1. Introduction

In this world of growing technologies everything has been computerized. With large number of work opportunities the Human workforce has increased. Thus there is a need of a system which can handle the data of such a large number of Employees. This project simplifies the task of maintaining records because of its user friendly nature. The objective of this project is to provide a comprehensive approach towards the management of employee information.

The objectives of this system include:

- Design of a web based HR management system to fulfil requirements such as project management, leave management, report generation to assist in performance appraisal, ESS and employee trainings.

- Well-designed database to store employee information.

- A user friendly front-end for the user to interact with the system.

- Modules specification:-

There are 4 types of modules:- 
- Account \& Administration

- Human Resource Information

- Client Management

- Project Management

\section{Features}

- This system will reduce the complexity of employee management.

- By using this system we can easily maintain all the records .

- It will reduce searching time.

- It can be easily handled by the person who has elementary knowledge of computer because it provides an user friendly environment.

- It is efficient to use

\section{SYSTEM ARCHITECTURE}

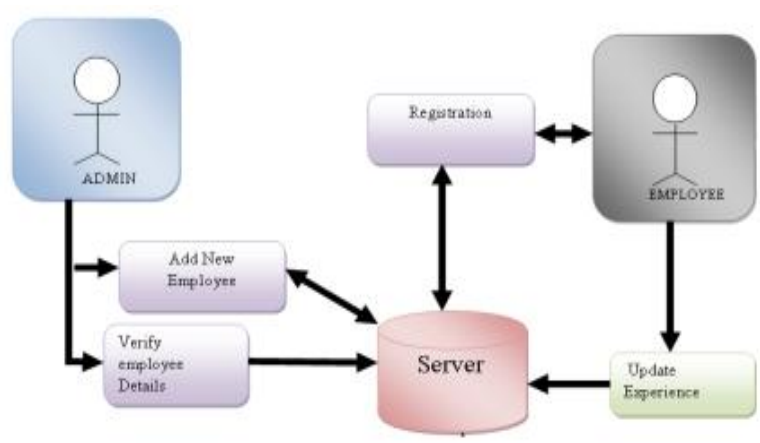

\section{CONCLUSION}

This chapter dealt with the user's needs and expectations for the new system. The next chapter deals with requirements analysis that is requirements needed to solve the problem being faced by the workshop in Rwanda. An employee managementsystem will be the best solution for the problem. It will provide easy online access to the employees that are currently at work and what they are working on. Also easy to allocate jobs to the employees that are done with what they were doing. The system will provide quick and reliable access to the running of the business saving the manager a whole lot of time and money.

\section{FUTURE SCOPE}

The designed system provides the HOD with the ability to assign tasks to project members. If further worked on, this functionality can assist in determining the performance of employees based on their ability to finish tasks on time.

\section{REFERENCES}

[1] OrangeHRM Open Source, Retrieved: November 4, 2013. From: http://www.orangehrm.com/open-source-product-featurespim.shtml

[2] A.S.SyedNavaz, A.S. SyedFiaz, C. Prabhadevi, V. Sangeetha, S. Gopalakrishnan, "Human Resource Management System", IOSR
Journal of Computer Engineering (IOSR-JCE), Volume 8, Issue 4 (Jan. - Feb. 2013) Page 62-71.

[3] Julie Bulmash, "Human Resource Management and Technology", Chapter 3

[4] TECH HRM (Human Resource Management System), Retrieved: November 4, 2013.2 From: http://www.techjetsolutions.com/brochure/TECHHRM.pdf

[5] Renae Broderick, John W. Boudreau, "Human resource management, information technology, and the competitive edge", Academy of Management Executive, 1992 Vol. 6 No. 2

[6] Centralized Employee Information, Retrieved: July 8th, 2014. From: https://www.zoho.com/people/employee-managementsystem.html

[7] HR and Employee Mnagement Software, Retrieved: July 8th, 2014. From: http://www.getapp.com/hr-employee-management-software

[8] Ian Sommerville, "Software Engineering", 9th Edition, AddisonWesley, 2011.

[9] What is Enterprise Resource Planning (ERP)? Webopedia. Retrieved: January 17, 2014, from: http://www.webopedia.com

[10] Avison, D. and Fitzgerald, G. (2003).Information systems Development Methodologies, Techniques and Tools.3rd Edition. McGraw-Hill Education Limited Bershire 